Sites of somatic subjectivity: E-scaped mental health promotion and the biopolitics of depression

\author{
Simone Fullagar \\ Griffith University, Australia
}

Social Theory and Health, 6(4), 323-341.

\begin{abstract}
$\underline{\text { Author Contact Details }}$
Dr Simone Fullagar

Department of Tourism, Leisure, Hotel and Sport Management

Nathan campus

Griffith University

Queensland, 4111
\end{abstract}

AUSTRALIA

Ph: +61 737356712

Fx: +61 737356743

Email: s.fullagar@griffith.edu.au 


\section{Sites of somatic subjectivity: E-scaped mental health promotion and the}

\section{biopolitics of depression}

\section{$\underline{\text { Abstract }}$}

The identification of depression as a global health problem has lead to the proliferation of websites providing information, advice and treatment pathways. As a form of e-scaped mental health promotion (Nettleton, 2004) these sites mobilise different discourses of depression to improve mental health literacy, help seeking and support. This article draws upon insights from governmentality and feminist theorists to examine how a high profile, publicly funded Australian website, Beyondblue (www.beyondblue.or.au) discursively constitutes depression as a problem for individuals and populations, such as women. Through a discursive analysis I considered how the website mobilised different forms of expertise as sources authority about depression and recovery. Although gender differences and social factors were acknowledged in relation to depressive experience, the self-certainty of biomedical language prevailed. Web users were urged to think about themselves primarily as somatic subjects with chemical deficits that required pharmacological or psychotherapeutic treatment (Novas and Rose, 2000). Although there were some discursive tensions arising from the representation of gender and depression, the website contained little critical engagement with different notions of mental health literacy. While acknowledging their partiality, feminist and governmentality perspectives can enable a more critical examination of how e-scaped mental health promotion initiatives actively participate in the formation of new kinds of somatic subjectivities.

Keywords: depression websites, mental health promotion, governmentality, somatic subjectivity, gender 


\section{Sites of somatic subjectivity: E-scaped mental health promotion and the biopolitics of depression}

\section{Introduction}

Over the last decade many industrialised countries have responded to the World Health Organisation's identification of depression as a growing and potentially large population health problem (Murray and Lopez, 1996). Australia responded by establishing a National Action Plan for Depression in 2000, which in turn, informed a range of mental health care and promotion initiatives that have recently been expanded with increased funding (websites, media campaigns, GP referral schemes, school \& community programs). The Action Plan was positioned as part of a broader mental health strategy aimed at reducing the social, personal and economic impacts of depression (Commonwealth Department of Health and Aged Care, 2000a). Although the primary focus was on clinical depression, the discursive boundaries of policy broadened to include milder depressive 'symptoms' as a prevention and intervention focus. These shifts suggest how a new language of 'depression' has begun to circulate through mental health policy and promotion initiatives that seek to reduce risk of illness, manage its effects and hence govern population distress and well-being within advanced liberal societies (Rose, 2007b; Moynihan and Cassels, 2005; Dowrick, 2004; Metzl, 2003).

This article builds upon sociological critiques of new forms of medicalisation to consider how e-scaped mental health promotion, as Sarah Nettleton coins the term, exists within a broader biopolitical terrain (Lupton, 1997; Nettleton and Burrows, 
2003; Nettleton, 2004). Through the positive intent of improving population 'mental health', e-scaped promotion initiatives actively constitute particular knowledges about health and illness, normality and pathology, through the virtual spaces of an Internet mediated social world. The significance of the Internet in shaping health beliefs and behaviours has been the subject of debates related to the potential democratising effect on access to information and implications of the digital divide (Broom, 2005). Critical discussions on the changing power-knowledge relations of expertise and trust that shape health and illness interactions and understandings have also emphasised the changing social context of heightened uncertainty and risk (Nettleton, 2004; Ayers and Kronenfeld, 2007). Mental health e-scapes are compelling sites for sociological analysis as they enable us to examine the language through which our very sense of subjectivity is problematised as being in ill, in need of expert intervention and requiring self-responsible practices that can restore normal functioning, social and economic participation (Busfield, 2006). In this article I acknowledge the partiality of all academic critique and undertake a discursive analysis of a prominent Australian website, Beyondblue (www.beyondblue.org.au). Situating my analysis within a poststructuralist tradition that refutes the assumption that language 'represents' truth, I consider how Beyondblue produces knowledge about the problem of, and solutions to, depression as ill health (Game, 1991). I also draw upon feminist critique that also identifies the gendered effects of mental health/illness discourses to consider the implications for how women’s subjectivities are positioned, and hence, rendered governable (Stoppard, 2000, Ussher, 1997). Epidemiological research has positioned depression as the leading cause of the non-fatal burden of disease for women in Australia and similar countries (Fullagar \& Gattuso, 2002; Australian Institute for Health and Welfare, 1999). In this sense, the Internet is a key site through which the 
power-knowledge relations of biomedical expertise articulate with women's emotional lives in the everyday creation of a new language of somatic subjectivity (Novas and Rose, 2000; Rose, 2007a; Rose, 2007b).

Rose (2007b) and others have argued within contemporary biocapitalism we are witnessing the rise of molecular science and the emergence of pharmacological solutions that are focused on altering the biochemistry of the somatic, or more specifically the neurochemical self (Healy, 1998; Crossley, 2003; Healy, 2004). The ethos of maximizing self-responsibility and minimizing the dysfunction of the contemporary biocitizen that informs mental health promotion is also gendered in relation to the care practices women are obliged to adopt in managing depression. This article endeavors to bring together feminist and governmentality insights to consider the implications of understanding the depressed woman as a somatic subject in need of intervention, improvement and risk management prevention. Starting with a broader discussion I consider the Beyondblue website as an example of e-scaped mental health promotion in light of debates about improving mental health literacy and the government of somatic selfhood.

\section{A Governmentality Perspective on E-scaped Mental Health Promotion}

Australian policy objectives have focused on increasing the population's mental health literacy, which is broadly defined as the ability to recognise mental health problems and seek professional (especially medical) help (Jorm et al., 1997; Jorm, 2000; Christensen and Griffiths, 2002). The key role of new communication technologies, such as the Internet, in disseminating mental health information was 
recognised through public funding to create the Beyondblue organisation and website as a national policy initiative in 2000. This site is similar to other initiatives developed elsewhere, such as the United Kingdom’s ‘Defeat Depression’ campaign (http://www.depression.org.uk). Government funding still supports Beyondblue however it operates as an independent company with a board of directors, a broad range of partnerships with other organisations and fundraising activities to support its strategic direction for 2010. The chairman of the board is a very well known and charismatic former politician and the organisation has a range of awareness raising and prevention activities, as well as funding programs for projects and research that appear on the website. Beyondblue's own evaluation claims that it has been highly effective in improving depression literacy levels within Australia ('Beyondblue: The way forward 2005-2010’ webpage).

Despite the recent proliferation of depression websites there has been surprisingly little critical analysis of the implications arising from health policies that utilise new e-scaped mental health promotion to enhance emotional well-being (Fullagar and Gattuso, 2002; Young et al., 2004). Research has largely focused on examining the ‘quality' of information about depression within an 'evidenced-based' medical framework (see Christensen \& Griffiths, 2002). This research is significant in that it identifies the varying quality of website information that is produced about the cause and treatment of depression. In fact, the Beyondblue site identifies itself as an authoritative source of quality information on depression through reference its citation within these publications. However, the reliance on an evidence base that only refers to particular kinds of expert knowledge (psychiatry and psychology) and standardised methods (randomised clinical trials) precludes a more critical examination of the 
biopolitical basis and gendered effects of depression information. Measures of quality tend to stem from epistemological questions concerned with 'what' depression treatments have 'scientifically' measured, rather than from broader questions about 'how' depression is itself mobilised within the discursive terrain of contemporary biopolitics. Hence, they do not open up critical questions about the different ways in which knowledge about depression is produced, nor do they engage with sociological or feminist perspectives that question dominant approaches.

In contrast to research on the quality of depression information I draw upon insights from governmentality theorists to problematise the power-knowledge relations that shape e-representations of depression and depressed subjects (Gabe, 1995; Dean, 1999; Rose, 1999; Novas and Rose, 2000). From this perspective website information cannot simply be considered to be simply a true or false representation and neither are seemingly objective forms of analysis ever impartial. Rather, web discourses make depression thinkable in particular ways that, in turn, may shape how a depressed subject may act to govern their own emotional distress. Novas \& Rose (2000) argue that biomedical discourses do not work in isolation but intersect with 'the norms of enterprising, self-actualising, responsible personhood that characterise "advanced liberal” societies, and with the ethics of health and illness that play such a key role in their production and organisation' (Novas \& Rose 2000, p. 488). Websites are part of a complex discursive field that positions the depressed subject not simply as a recipient of information but rather as a responsible, risk reducing, help-seeking consumer. Web users exercise power through actively questioning, seeking and refusing types of information and expertise in ways that position them well beyond the passive confines of the traditional sick role and the historic walls of the psychiatric 
institution (Lupton, 1997). This is a subject position that works to actively align the individual's desire for wellness, treatment, cure or healing with an assemblage of medical, epidemiological and psy-expertise that constitutes the e-scaped terrain of depression literacy (Busfield, 2001; Nettleton and Burrows, 2003; Rose, 2005).

The wide range of material available on the Beyondblue site includes fact sheets, selfassessment checklists, recommended reading and web links, discussion boards and community event lists that have been created by medical and therapeutic experts, people with depression themselves, researchers with links to pharmaceutical companies and a range of services and self-help groups. While this bricolage of information can be viewed as part of the democratising effect of the Internet it also highlights the biopolitical context that mediates all communication about mental health and illness. Websites also draw upon sources of authority that mobilise particular truths about the aetiology of depression, treatment pathways and hence the depressed self. The everyday and academic practices of actively 'consuming' or critically analysing e-scaped mental health promotion information are highly temporal and the discursive context changeable. However, I situate my analysis of the Beyondblue site within the particular time-space moment of July 2007 to consider the biopolitical effects, yet without assuming the site is static or simply reducible to one 'reading' (Hermes, 1995). This analysis does not claim to be representative of some objective truth that exists beyond my interpretive stance. It extends and refines my previous investigation of a wider range of depression websites and popular media representations (Young et al., 2004; Gattuso et al., 2005). 
During July 2007 the Beyondblue site was examined through a discursive analysis that examined how each page mobilised particular 'statements' about the cause, management and prevention of depression (see also Alvesson and Skoldberg, 2000; Mason, 2002; Day and Keys, 2008). Particular attention was payed to the nature of authority and expertise used to present helpful information on depression (eg, biomedical, psychological, social or experiential). Importantly, what was not said was also considered in terms of the gaps and silences that point towards other kinds of knowledge with different explanations about emotional distress, the social relations of depression and embodied subjectivity. Working within a post-structuralist tradition I employ the method of interweaving website examples with ways of thinking about the processes that produce somatic selfhood (Rose, 2007b). This approach offers a means of bringing together different registers of meaning and problematising the truth of escaped mental heath promotion initiatives (Alvesson and Skoldberg, 2000).

The Beyondblue website does not stand alone but is integrally linked to a range of social marketing and promotion strategies, such as, posters on buses, celebrity endorsement, advertisements on television, radio and in newspapers, as well as workshops and consumer forums. Entering via the www.beyondblue.org.au homepage web users find entry points relating to information about depression and help seeking pathways ('Find a doctor or psychologist'). These range from, 'Did you know - one in five people experience depression at some point in their life', 'Do you have depression? Complete an interactive checklist', see our 'Beyondblue Fact Sheets on a range of depression related topics', as well as 'News' and stories on 'SAD more than the winter blues' and 'Don't beat about the bush' drought initiative. Engaging in a general Google search in July 2007 brings up Beyondblue as the first depression web 
site along with a range of other personal web pages, self-help sites and those started by health professionals. Entering the Beyondblue site this way directs web users straight to the page 'What is depression?' which contains a self assessment checklist that can identify if you are 'suffering a depressive illness' (http://www.beyondblue.org.au/index. aspx?linkid=1.3\&gclid= CKfy9reVjY0CFRoRYQod2h3Kng, accessed 4/7/2007). Right from this point of entry into the website individuals are invited to understand their emotional distress through the diagnostic category of depression.

The Beyondblue e-scape is articulated through the medicalised language of depression as a 'serious mental illness' that requires specific treatments to prevent the likelihood of recurrence and to restore functioning. The 'Understanding depression page' outlines several treatment options with an individualised emphasis on finding what works and treating the cause of depression rather than finding temporary relief. Web users are invited to interpret their experience through a short checklist to determine if they have been constantly sad, miserable or lost interest in usual activities over two weeks and, with experience of at least 3 of 28 symptoms (behaviour, thoughts, feelings and physical). Once this relation to self as depressed is established through expert self-assessment the site explains how a range of 'situations and events' can combine to make an individual more at risk (family conflict, isolation, unemployment, illness, drug use, brain and chemical changes, depressed family member). In addition, more women (1 in 4) than men (1 in 6) are identified as likely to experience depression in their lives. This list of biopsychosocial risk factors works to signify the broader context that impacts on individual depression. 
In attempting to invoke social, psychological and biochemical discourses the site avoids common criticisms about the promotion of a highly reductionist view of depression as a problem of chemical imbalances in the brain (Wiener, 2005). However, delving further into the detailed explanation of what causes depression, as I shall examine next, there are particular risk discourses that repeatedly invoke a neurochemical notion of self. On Beyondblue understanding depression involves knowing how different kinds of depression are linked to specific treatment options that include: exercise for mild depression, psychological (eg, CBT) and medication for more severe depression. Assumptions about the severity of depression are interconnected with a medicalised view of expert treatment. Drug treatments are described as 'not addictive' and concerns about side effects are countered by the risk of depression becoming worse if left untreated. Further details on Fact Sheets can be found about anti-depressants and exercise, so we shall return to consider those prescriptions for self-management and recovery later in the discussion.

Information on seeking support from family and professionals is provided as well as tips on how to help someone else. A number of web links to other depression prevention sites are listed but curiously the popular DepressionNet site (www.depressionnet.com.au, set up by people with depression themselves in 1997) is not evident. It would appear that only certain sites are linked if they adhere to an implicit evidence based standard and assumptions about quality mental health information (Christensen et al., 2000). The discursive borders of mental health promotion are firmly established through highly normalised pathways for understanding depression as an individual illness requiring particular kinds of expertise to understand and treat it effectively. There are no links to alternative e- 
scaped mental health sites, different solutions, self-care practices or critical debates about conventional treatment: the site evokes a disciplined, responsible subject position tied to ill health via e-diagnosis. At this point web users may desire further understanding about the cause of depression to ensure they are adopting the treatment regime that most closely aligns with their individual experience as somatic subjects. The most relevant page can be found amongst the long list of Fact Sheets, 'What causes depression?' (Fact sheet 3). Before we turn to this page I want to begin by exploring the usefulness of Rose's (2007) notion of somatic individuality as it figures within mental health discourses specifically as a neurochemical self that requires biochemical enhancement and alteration.

\section{Sites of Somatic Subjectivity}

Extending Foucault's (1991) work on biopolitics as the exercise of power through the administration of life via populations and bodies, Rose (2001; 2007a) argues that contemporary notions of selfhood have become intrinsically somatic. The body has emerged as a key site through which individuals are urged to work on themselves, and are worked upon, through an array of biopolitical forces that link up the domains of medicine, lifestyle practices and social networks. As somatic individuals biocitizens within advanced liberal societies are increasingly urged to understand their physical and mental health or illness through the molecular discourses of medicine and life sciences (biochemistry, genetics etc). Biopolitical forces are reconstituting the 'ill or diseased self' via new practices of diagnosis, treatment and self-management that are now increasingly e-scaped within cyber representations and interactions that render the molecular substance of the biomedical body even more visible (Rose 2007b; 
Nettleton, 2004). With reference to mental health Rose (2007b) argues that the rise of molecular science, the new genetics and the proliferation of pharmacological 'solutions' has created the conditions for the emergence new somatic identities such as the 'neurochemical self'. The Beyondblue website positions the neurochemically deficient self as central to their explanation of 'What causes depression?' (Fact Sheet 3). The discourse of depression as a chemical imbalance in the brain is represented through the use of visual images of the body to signify how 'recent events + personal factors' impact on the brain that is positioned at the centre of the problematic self. The factors that are listed outside the body with arrows pointing towards the brain include, 'life stressors, drugs and alcohol, past bad experiences, personality, high anxiety, chemical changes and family (inherited) disposition'. Underneath the deficient brain there is, ironically, a box labelled 'medical illness/ and/or treatment' that works to implicitly link the possible solutions (not stated but assumed to be anti-depressants). This kind of visualisation of depression works to remap the surfaces of knowledge that make up what we understand to be the somatic self. In this way, the website works to actively engage subjects in re-describing the relation between mind and body.

Such representations of the biochemical substance of depression are part of broader transformations within psychopharmacology that Novas \& Rose (2000, p.491) argue have changed the features that appear to define individual subjectivity (particularly mood and personality) as they become amenable to anti-depressants such as Prozac. What disappears in such models is the experience of self with its complex emotions and relational context of everyday life that extends well beyond the identified psychological notions of 'family or interpersonal conflict, loss and high-risk 
personality', or medical causes 'pain, thyroid function, brain injuries, cancer, infectious diseases, blood vessel disease in the brain, steroid \& hormonal treatments, quitting smoking'. The neurochemically depressed subject is also a risky self with a problematic genetic history, illnesses or personality type that requires self responsible action to address the individualised cause of dysfunction (another webpage discusses 'What puts a person at risk'). The website's visual metaphors that evoke a dysfunctional brain are made more 'truthful' through the neurochemical language of diagnosis and treatment that is represented through the list of 'common tests done by a doctor - full blood count and biochemistry, thyroid function, urine test for sugar and protein and occasionally a brain scan'. Although a disclaimer is made about the difficulty of identifying the cause of depression there is little discursive space allowed for doubt or critique in relation to diagnosis or treatment options. Web users are urged to 'seek help' to ensure the get treatment for a 'faster recovery'.

Web users might then wish to examine more closely the information on ‘Antidepressant medication' (Fact Sheet 11) to understand how they may expertly address their own neurochemcial lack. The website explains how antidepressants work when 'someone is depressed, they have lower levels of brain chemicals such as serotonin, noradrenaline and dopamine. This makes it more difficult for messages to be conveyed within the brain. Antidepressant medication is designed to correct this imbalance, which helps the brain function in a normal way’. Advice suggests that medication is most appropriate for those with moderate to severe depression and is often used along with psychological treatments, although it is not recommended for those under 18 years. Issues for pregnant and breastfeeding women are also raised in relation to potential risks and several pages are provided on the details of different 
drugs; how they target symptoms, potential side effects and how 'effective' they have been within clinical research trials. This pharmacological discourse directly connects 'depression as illness' to 'treatment' options that require particular kinds of professional intervention within the highly profitable fields of mental health and medicine (Healy, 2004; Busfield, 2006). In this way the nature of depression is calculated as a somatic 'lack' through a diagnosis that quantifies behavioural symptomatology, and yet can be rebalanced through anti-depressant medication.

The antidepressant webpage clearly uses an evidence based medicine framework for determining the quality of advice, the nature of risk and potential benefits. The doctor is positioned as the key point of support and advice about medication use and links to a range of other (publicly funded) psychological and allied health professionals are provided. Web users are again urged to consider that antidepressants are 'safe, affective and not addictive' and are advised that length of treatment depends upon the severity of the illness: a 12 month period is considered a normal 'short' timeframe. However, for others with chronic depression there is a medical analogy that again articulates biomedical origins, 'antidepressants are needed on an ongoing basis - in the same way that someone with diabetes would use insulin or someone with asthma would use respiratory medication'. Yet, there is no advice concerning what to do if the evidence based drugs fail to work effectively, if personality traits are impervious to therapeutic invention, if diseases persist and family history or loss is unavoidable. This discursive silence raises the question of how the failure of biomedical promises might individually and collectively affect depressed persons sense of hope for a future identity beyond neurochemical lack, personality deficit and therapeutic alliances? 
Curiously the limits of biomedical discourses are implied in advice related to non-medical self-help recovery practices, for example 'Recovery’ (Fact Sheet 15) and 'Keeping active’ (Fact Sheet 8). Alongside the biomedical discourses of treatment are discourses that invoke experiential expertise as important in the self-management depression in terms of emotions, social relationships, developing a healthy lifestyle and stressful situations (job loss, financial difficulties). A range of technologies of self are cited in these web pages that emphasise the cultivation of new habits of selfhood, such as, balanced lifestyle routines, finding support groups, generating motivation to be active and social as well as regular healthy eating. Web users are offered a number of different planning tools that enable the scheduling and calculation of new activities into a weekly timetable. While this experiential discourse still positions depression as an individual responsibility it does disrupt the singular truth of biochemical origins as it identifies a whole host of everyday practices and social situations that inform that material conditions of recovery, and hence depression itself.

The potential tension between experiential and biomedical discourses is partly resolved by the incorporation of 'exercise' and other practices into the language of treatment regimes and normalised pathways through the medical or allied health professional. In this way non-medical options, such as exercise, are recouped as a prescriptive means of redressing chemical imbalances ('Exercise may increase levels of neurotransmitters (chemical messengers in the brain) that have been found to be in short supply in depressed people'), rather than evoking ethical questions about one’s life experiences and identity. However, I suggest that different discourses about recovery from, and management of, depression can work to open up other ways of thinking about somatic subjectivity beyond the reduction of the depressed self to the dysfunctional brain. The experiential knowledge of the subject 
draws upon a mind-body relation that also brings into play another way of 'seeing' the materiality of depression beyond the molecular optic. In other words, the Beyondblue recovery practices are highly normalised in their aims to restore functioning and selfresponsibility through adherence to medical expertise, but they may also reposition depression and start to make visible the everyday social world that affects emotional wellbeing and mental health. Next I turn to consider more directly how gender is made visible within the Beyondblue website as a point of similarity and difference from other web pages.

\section{A Feminist Analysis of Depression E-scapes}

If you are a woman web user seeking gender specific information on depression you will only find several key reference points to orient your self-understanding. First, repeated throughout the Beyondblue site is a dominant epidemiological discourse about gender differences in depression rates, 'From puberty onwards, women are twice as likely to experience depression as men’ ('What puts a person at risk of depression webpage) and more women (1 in 4) than men (1 in 6) are identified as likely to experience depression in their lives ('Understanding depression’ webpage). This representation of gender issues related mirrors mental health policies that position women as a population at risk of depression with rates of diagnosis identified as higher than those of men (Australian Institute for Health and Welfare, 1999). The risk of depression for women is at once universalised and individualised through epidemiological discourses that calculate the probability of depression over a lifetime. When gender was identified it was specifically in relation to 'female specific' 
problems of the body, hormones and role changes. For example, on the Beyondblue 'What puts a person at risk' page it talks specifically about 'women' when it states, Depression is more common in younger rather than older women. Women who are likely to develop depression will usually experience their first episode during their reproductive years between the ages of 15 and 45 years. While women may experience all types of depressive illnesses, there are certain types of depression that are specific to women: postnatal depression: depression which is common after childbirth and varies from mild to severe pre-menstrual dysphoric disorder (PMDD): 3 to 5 per cent of women experience depression before their periods. This can involve fatigue, anxiety, tension, mood swings, depression, feeling overwhelmed or out of control. It should not be confused with 'Premenstrual stress' (PMS) as PMDD symptoms are far more severe than PMS symptoms post-menopausal: depression may become more severe after menopause in some women.

http://www.beyondblue.org.au/index.aspx?link_id=89.585, accessed 4/07/2007)

This account suggests that women's experience of depression emerges out of a biologically disordered femininity. Such ‘information’ may in fact exacerbate women’s feelings of shame, imperfection and failure to achieve normalised ideals (Ussher, 2004). There is, however, an interesting counter point to the biomedical view that is evident within the web page on 'Postnatal depression' (Fact Sheet 22). Rather than emphasise the hormonal or biochemical changes related to pregnancy and birth, this page refers to motherhood as a significant life changing event and how 'adjusting to life as a mother can be difficult'. Even in the long list of factors and events that are identified as 'causing' PND there is no 
deference to singular explanations or disguised biomedical claims. Women can complete the Edinburgh Postnatal Depression Scale on-line and they are told that PND has the 'same signs and symptoms as depression’. This discursive shift towards an understanding of depression as related to the gendered experiences in women's lives is very interesting as it creates a tension between the previous explanations of depression as primarily biochemical. Women are presented with medical and therapeutic advice but they are also offered a range of other self-help strategies that involve social support, time out for oneself and partner responsibility. Through its connection to motherhood PND is clearly linked to the gendered responsibilities and demands on women's lives in ways that other types of depression are not always so evident. Despite these brief moments of connection between depression and women's lives, overall the Beyondblue website fails to engage in any kind of gender analysis.

There were no web pages that discussed in any detail gender and social inequalities, or even mentioned the existence of critiques of biomedical discourses that decades of social research has generated in relation to women's experience of depression (Mc Grath et al., 1990; Russell, 1995; Stoppard, 2000; McMullen, 2003; Stoppard and Gemmell, 2003; Stoppard and McMullen, 2003; Blum and Stracuzzi, 2004; Metzl and Angel, 2004). The absence of a gendered analysis of depression as a social phenomena also suggests that Beyondblue positions itself within a divided biopolitical space that serves to maintain a hierarchy of truth despite other policy areas dealing with the same issues within a women's health framework (New South Wales Department of Health, 2002), and links to sites outside Australia that address these issues in different ways (www.apa.org/pi/wpo/women\&depression). The invisibility of power relations, structural pressures and gender inequities that can give rise to emotional distress and depression for 
women means that Internet users are oriented towards highly individualised understandings of depression as a somatic disorder that is biochemical and implicitly sexed.

Although Rose (2007, p. 210) makes passing reference to women as neurochemical selves there has been little analyses of the gendered nature of somatic individuality. The point at which a feminist reading becomes particularly significant is in relation to the process of cultural inscription and self-governance implicated in the formation of feminine subjectivities that are centred on new mind-body relations. Novas \& Rose make this point about the way in which clinical 'risk' figures in the formation of selfhood. They argue that, 'Individuals act upon the inscriptions of clinical risk which mark their bodies and define them as particular kinds of subjects’ (Novas \& Rose 2000, p. 507). Websites work in this way as sites of subjectification where individual women web users engage in the process of 'enfolding' exterior discourses about biomedical and psychological risk into an interiorised notion of self (enfolding to various degrees and/or refusing) (Rose, 1990). The enfolding of depression is mediated by the technologies employed by websites that invite completion of self assessment surveys and questionnaires, reading one’s own signs of emotional distress against clinical categories of symptomatology and engaging with the search for a biomedical origin of depression. These practices of diagnosing the self entail a redefinition of the interiority of emotional distress as ‘depression' that can indeed bring relief for some women (e.g., I am sad all the time because of the imbalance in my brain, not because I am viewed as an incompetent mother, wife, woman etc). This new relation to the gendered self as 'ill' or 'chemically imbalanced' is articulated through a visual metaphor - a 'molecular optic' - whose substance is biochemical (e.g., I see myself as lacking in brain chemicals rather than struggling with identity or 
gendered responsibilities). In this light the promise of anti-depressants becomes even more powerful as a means of righting inherent wrongs in the molecular substance of femininity itself.

In taking up these contemporary forms of somatic individuality depressed women can re-imagine themselves as lacking in ways that echo and differ from previous generations of female hysterics who sought out psychoanalysis to remedy problems thought to stem from irrational 'feminine desires' (for other kinds of relationships, independence and freedom)(Ussher, 1991). Being ill with depression today and taking up responsibility to seek out treatment mobilises women to continue to embody a culturally valued desire to become 'good' women, since brain chemistry is the problem not the social world. Through this subject position they can potentially maintain agency since they become active partners in the new modalities of brain science and psy-expertise and, through accessing the websites, they become members of a virtual community, speaking to desires for connectedness that are not met elsewhere. In this way the depressed subject is not simply positioned as a passive recipient of professional knowledge, rather she is obliged to become active in aligning her desire to recover 'balance' and reduce the risk of recurrence through developing individual and social life strategies. This pathway positions women within a network of professional surveillance and authority that cannot 'see' beyond the molecular to the social nature of depression. More critical ways of making sense of depression as a relation to the somatic self as a gendered, embodied and emotional signifier of dissatisfaction with the gendered experience of feminine subjectivity remain unseen. Instead the relationship between the female self and body becomes the site of new ethical problematisations for professionals and individuals concerning how to 'treat' 
mood disorder as a biochemical or personality lack. An opportunity is thus lost to explore the complex interrelationships between mind and body as lived and discursive phenomenon: the embodiment of depression as a biological and social production (Wilson, 2004).

This emphasis on activating the responsible feminine self into seeking help also overlooks the possibility that the depressed woman who lacks motivation and energy, or refuses to accept medication and biomedical guidance, could be engaged in a kind of refusal to cooperate with the social demands that have produced her emotional distress (Ussher, 1997). The recognition of an active feminine subjectivity is crucial in considering the potential for other knowledges and practices of freedom that may invoke different relations to the somatic self and hence depression. Despite Beyondblue’s claim to promote ‘consumer' involvement (Blue voices initiative) there is an interesting lack of engagement with discourses mobilised by women in the 'mental health consumer movement' that reflect alternative constructions of mental illness that differ from dominant biomedical formulations (Pinches, 2004). Indeed, the consumer and women's movements have by and large resisted the 'pathologising' of mental health issues by offering new ways of seeing things, rather than reducing the person to an illness identity.

\section{Discussion and concluding remarks}

Current Australian policy directions promoting mental health literacy appear to be relatively successful in achieving their aims and circulating biomedical expertise through e-scaped depression initiatives, such as Beyondblue. However, the implications of the 
proliferation of biomedical discourses about causality and treatment for women identifying as depressed have not been critically considered. This raises further issues for e-scaped mental health promotion approaches that commonly assume that the interpretation and communication of health messages are transparent, rational processes with measurable outcomes identifiable as low or high levels of population mental health literacy (Jorm, 2000). In fact, we need to know much more abut how depression websites are read, used within health practices and critically interpreted in relation to different sources of expertise (biomedical, psychological, social, experiential, natural medicine etc) about depression and its management. This would enable the possibility of a more democratic e-scaped mental health terrain that would embrace a greater plurality of voices, issues and ways of understanding the problem of depression. While previous eras have understood depression as a problem of 'mind' (Busfield 2001) the contemporary formation of depression recasts the problem of mood disorders in terms of a neurochemical relation of psyche-self to the brain-body. Metaphors of 'homeostasis and balance' permeate the pharmacological cure for depression and by extension suggest that individual's 'moods' or emotional lives can similarly be rebalanced (rather than changed or questioned) through chemical regulation of the body. Yet, it is a depressed body that is strangely devoid of a relation to the feeling self : depressed moods figure only as a neurochemcial disruption rather than a sign of any cultural dis-ease.

It would be naive to consider that discourses about depression experience, causality and treatment/management can simply be measured and assessed in terms of evidenced based 'quality', as they are steeped in biopolitics. E-scaped depression sites actively participate in the government of mental health and illness, normality and pathology whether they acknowledge these power/knowledge relations or ignore them. They work to shape, in 
highly normalised and medicalised ways, women’s thinking and conduct in everyday relations with self and others (Rose, 1996; Rose, 1998). As such they participate in the creation of a feminised form of somatic individuality that reinforces a neurochemcial notion of lack at the centre of women's depressed subjectivity. But at the same time they activate women's sense of agency to align their desire for recovery with highly prescriptive help-seeking practices that have emerged out of new biomedical discourses that rely heavily upon anti-depressants and cognitive therapies. Women's individual responsibility for seeking help for depression is positively associated with overcoming deficit and imbalance within a femininised biomedical body that is itself the locus of mental health risk, and hence, intervention. I argue that this notion of mental health risk reiterates a negative relation to the affective and embodied self. It is premised on a problematic neurochemical self that requires ongoing discipline via expertise and self-help to improve functioning according to normalised feminine ideals (the seductive promise of antidepressants that make one into a normal woman again). This analysis supports the insights of recent research into the gendered representations of Prozac within periodical articles that identified how anti-depressants participated in the perpetuation of a new feminine ideal where women exercised a highly disciplined relation to the body (Blum and Straccuzi, 2004; Metzl, 2003). The body is central to a productive notion of the feminine self that can participate competitively in the new economy and manage the often conflicting demands of employers and families. This raises the question of what kind of moral judgements will be made about women who 'fail' to follow the disciplinary regimes of biomedical, psychological or even self-help treatments?

The emphasis on locating a biochemical substance or truth within the somatic self is often justified in term of moving depression away from moral judgements ('it is an illness just 
like diabetes') about individual coping or character weakness to a normalised view of mental illness. The Beyondblue depression website mobilises biomedicine against the social 'stigma' which they argue surrounds depression as a mental illness ('Beyondblue: The way forward 2005-2010' web page). In this context women are not positioned as failed moral subjects because they have depression as it is a treatable illness. They are repositioned as successful help seekers and self-managers who exercise responsible, rational choices about medical and psychological interventions to improve their mental wellbeing. Managing one's emotional distress through anti-depressants becomes a riskreducing imperative that ensures the modern woman's productivity is maintained in the life domains of work, family relations and home. There is also an important intersection here between the rationalities informing a globalised pharmaceutical market where antidepressant solutions make for highly profitable industries and a burgeoning governmentsupported pharmaceutical benefits schemes (Healy, 1998; Sparks, 2002; Busfield, 2006).

It is highly debatable whether 'knowing' that depression is a biochemical malfunction actually works to counter social stigma. In fact, it may actually intensify shame through a sense that one's somatic self as a woman is biologically or genetically flawed. This sense of being flawed may extend to concerns about future generations where it becomes 'known' that depression has a genetic basis (e.g. bipolar disorder or generational depression in families). Health promotion and prevention initiatives that seek to reduce the social stigma of depression through biomedical pathways may very well be contributing to the creation of new practices of social exclusion based upon genetic and biological risk. In mobilising the molecular metaphors of somatic individuality as the active, defining substance of self, there is little opportunity for women to envisage their identities as social subjects and relational beings (beyond the prescribed professional help-seeking networks). 
We need to also consider these implications for women in relation to a genealogy of psychiatric disorders, such as hysteria, where feminine subjectivity has been linked to somatic 'lack' at different historical junctures. The implications of the rise of somatic individuality for women experiencing emotional distress are enormously complex when we consider the social context of violence, abuse, discrimination that intersects with the imperative for women to take up more responsibility for their own and others' wellbeing. There are enormously important opportunities for websites to engage more critically with a range of knowledges about depression. This said, we also need to question the extent to which the e-scapes of depression prevention actively participate in the growth of depression as a contemporary medical phenomenon.

In relation to deepening our sociological understanding of depression the work of governmenatality theorists such as Rose (2007b), Novas \& Rose (2000) is particularly useful in identifying the effects of new genetic discourses on reshaping the very way in which we 'see' health disorders. However, there has been little analysis of the gendered implications of new formations of 'human' subjectivity or life itself. To identify the effects of the intensification of the molecular gaze on the self there needs to be a gendered understanding of how somatic individuality is constituted differently in relation to sexed bodies and minds. As feminist analysis has shown there exist complex gendered processes that implicitly reengineer life in different ways for men and women (Grosz, 1994; Waldby, 2000; Metzl, 2003). Vitally important insights have been produced by feminist research that has identified the repressive, medicalising effects of expert discourses on women's depression in terms of pacifying and subjugating agency. Yet, often they have under estimated the productive nature of 
power relations that govern by 'making up', and hence producing rather than repressing, feminine subjectivities (Sparks, 2002). In this sense, the intersection of women's depressive experiences with the complex field of biopolitical rationalities, organised around the identification and reduction of health risk, brings into being new ethical problematisations for and about women's embodied selves (Novas \& Rose 2000, p 490). We need to further understand how e-health promotion discourses about women's depression are produced through contemporary biopolitics as a key sites for the creation of the active feminine subject who engages in the government of their own and others wellbeing. By ignoring the gender relations of depression websites fail to question the structural inequities, cultural responsibilities and expectations within advanced liberal societies that are implicated in the formation of depression itself.

\section{$\underline{\text { Acknowledgements }}$}

I would like to thank Suzy Gattuso for her thoughtful advice on an earlier draft of this paper.

Word count for main text and abstract, excluding references: 7153 words, $7 / 4 / 2008$

\section{REFERENCESReferences}

Alvesson M, Skoldberg K (2000). Reflexive Methodology: New vistas for qualitative research. London: Sage.

Australian Institute for Health and Welfare (1999). The burden of disease and injury in Australia. Australian Institute for Health and Welfare: Canberra.

Ayers S, Kronenfeld J (2007). Chronic illness and health-seeking information on the Internet. Health 11: 327-347. 
Blum L, Stracuzzi N (2004). Gender in the Prozac nation: Popular discourse and productive femininity. Gender and Society 18: 269-286.

Broom A (2005). The eMale: Prostate cancer, masculinity and online support as a challenge to medical expertise. Journal of Sociology 41: 87-104.

Busfield J (2001). Rethinking the sociology of mental health. London: Blackwell.

Busfield J (2006). Pills, power, people: Sociological understandings of the pharmaceutical industry. Sociology 40: 297-314.

Christensen H, Griffiths K, Medway J (2000). Sites for depression on the web: A comparison of consumer, professional and commercial sites. Australian and New Zealand Journal of Public Health 24: 396-400.

Christensen H, Griffiths KM (2002). The prevention of depression using the internet. Medical Journal of Australia S122-S125.

Commonwealth Department of Health and Aged Care (2000a). National Action Plan for Depression 1998-2003. AIHW \& CDHAC: Canberra.

Crossley N (2003). Prozac nation and the biochemical self: A critique. In: Williams, S, Burke, L, Bendelow, G, (ed). Debating biology: Sociological reflections on health, medicine and society, London: Routledge. pp 245258.

Day K, Keys T (2008). Starving in cyberspace: A discourse analysis of proeating-disorder websites. Journal of Gender Studies 17: 1-15.

Dean M (1999). Governmentality: Power and rule in modern society. London: Sage.

Fullagar S, Gattuso S (2002). Rethinking gender, risk and depression within Australian mental health policy. Australian e-Journal for the Advancement of Mental Health 1: www.auseinet.com/journal/vol1iss3/fullagar.pdf.

Gabe $J$ (1995). Health, medicine and risk: The need for a sociological approach. In: Gabe, J, (ed). Medicine, Health and Risk: Sociological Approaches, Oxford: Blackwell. pp 1-17.

Game A (1991). Undoing the social: Towards a deconstructive sociology. Milton Keynes: Open University Press.

Gattuso S, Fullagar S, Young I (2005). Speaking of women's 'nameless misery': The everyday construction of depression in Australian women's magazines. Social Science and Medicine 61: 1640-1648.

Grosz E (1994). Volatile bodies: Towards a corporeal feminism. Sydney: Allen and Unwin.

Healy D (1998). The anti-depressant era. Cambridge: Harvard University Press.

Healy D (2004). Let them eat Prozac: The unhealthy relationship between the pharmaceutical industry and depression. New York: New York University Press.

Hermes J (1995). Reading women's magazines: An analysis of everyday media use. Cambridge: Polity Press.

Jorm A (2000). Mental health literacy: Public knowledge and beliefs about mental disorders. British Journal of Psychiatry 177: 396-401.

Jorm A, Korten A, Jacomb P, et al (1997). Mental health literacy: A survey of the public's ability to recognise mental disorders and their beliefs about the effectiveness of treatment. In Medical Journal of Australia, pp. 182186.

Lupton D (1997). Foucault and the medicalisation critique. In: Peterson, AaB, R., (ed). Foucault, health and medicine, London: Routledge. pp 94-110. 
Mason G (2002). The Spectacle of Violence: Homophobia, Gender and Knowledge. London: Routledge.

Mc Grath E, Puryear Keita G, Strickland B, Felipe Russo N (1990). Women and depression: Risk factors and treatment issues. Washington: American Psychological Association.

McMullen L (2003). 'Depressed' women's constructions of the deficient self. In: Stoppard, J, McMullen, L, (eds). Situating sadness: Women and depression in social context, New York: New York University Press. pp 17-38.

Metzl J (2003). Prozac on the couch: Prescribing gender in the era of wonder drugs. Duke University Press: Durham.

Metzl J, Angel J (2004). Assessing the impact of SSRI antidepressants on popular notions of women's depressive illness. Social Science and Medicine 58: 577-584.

Nettleton S (2004). The emergence of e-scaped medicine. Sociology 38: 661-679.

Nettleton S, Burrows R (2003). E-Scaped medicine? Information, reflexivity and health. Critical Social Policy 23: 165-185.

New South Wales Department of Health (2002). NSW Women's Health Outcomes Framework. NSW Health: Sydney.

Novas C, Rose N (2000). Genetic risk and the birth of the somatic individual. Economy and Society 29: 485-513.

Pinches A (2004). Pathfinders: Community participation in mental health and other services. Northern Area Health Service: Melbourne.

Rose N (1990). Governing the soul: The shaping of the private self. London: Routledge.

Rose N (1996). Inventing ourselves: Psychology, power and personhood. Cambridge: Cambridge University Press.

Rose N (1998). Governing risky individuals: The role of psychiatry in new regimes of control. Psychiatry, Psychology and Law 5: 177-195.

Rose N (1999). The powers of freedom: Reframing political thought. Cambridge: Cambridge University Press.

Rose N (2001). The politics of life itself. Theory, Culture and Society 18: 1-30.

Rose $N$ (2005). In search of certainty: Risk management in a biological age. Journal of Public Mental Health 4: 14-22.

Rose N (2007a). Molecular biopolitics, Somatic ethics and the spirit of biocapital. Social Theory and Health 5: 3-30.

Rose N (2007b). The Politics of Life Itself: Biomedicine, power and subjectivity in the twenty-first century. Princeton University Press: Princeton.

Russell D (1995). Women, madness and medicine. Cambridge: Polity Press.

Sparks J (2002). Taking a stand: Challenging medical dominance. Journal of Marital and Family Therapy 28: 51-59.

Stoppard J (2000). Understanding depression: Feminist social constructionist approaches. London: Routledge.

Stoppard J, Gemmell J (2003). Depressed women's treatment experiences. In: McMullen, L, Stoppard, J, (eds). Situating Sadness, New York: New York University Press. pp 39-61.

Stoppard J, McMullen L (2003). Situating sadness: Women and depression in social context. New York: New York University Press.

Ussher J (1991). Women's madness: Misogyny or mental illness? New York: Havester Wheatsheaf. 
Ussher J (1997). Body talk: The material and discursive regulation of sexuality, madness and reproduction. London: Routledge.

Ussher J (2004). Premenstrual syndrome and self-policing: Ruptures in selfsilencing leading to increased self-surveillance and blaming of the body. Social Theory and Health 2: 254-269.

Waldby C (2000). The visible human project. London: Routledge.

Wiener $D$ (2005). Antipsychiatric activism and feminism: the use of film and text to question biomedicine. Journal of Public Mental Health 4: 42-47.

Wilson E (2004). Psychosomatic: Feminism and the neurological body. Durham, NC: Duke University Press.

Young I, Gattuso S, Fullagar S (2004). Women on the web: A feminist reading of depression prevention websites. In: Whiteford, G, (ed). Qualitative Research as Interpretive Practice, Bathurst: Centre for Research in Professional Practice, Charles Sturt University. pp 